\title{
THE RELEVANCE OF LEADERSHIP STYLES IN THE QUALITY OF EARLY CHILDHOOD EDUCATORS: A MULTIPLE CASES STUDY
}

\author{
Emilio Rodríguez-Ponce ${ }^{1}, \&$ Liliana Pedraja-Rejas ${ }^{2}$ \\ ${ }^{1}$ Instituto de Alta Investigación, Universidad de Tarapacá (Chile) \\ ${ }^{2}$ Departamento de Ingeniería Industrial, Universidad de Tarapacá (Chile)
}

\begin{abstract}
The purpose of this research is to analyze whether the leadership style of academic department's directors is relevant or not to explain the quality of the childhood educator's initial teaching. To this end, a study of three programs of early childhood educator's teaching conducted by different university institutions from Chile is carried out using Yin's recommendations (2014) to build the study and achieve internal validity, external validity, and reliability.

The research findings show that the transformational leadership style is associated with a better quality of the formative processes. The relationships found reveal that the inspiring motivation, intellectual stimulation, and individual consideration of the director of the department on which the teachers depend, influences in their degree of commitment, preparation, and in the effort of the teachers in their classes and in their relationship with the students.

These results are consistent with state of the art, except for the fact that, in this research, the charisma of the director of the department does not seem to be a differentiating element that influences the quality of the formative processes. In turn, it should be noted that the originality of this research lies in the fact that the impact of leadership styles is applied specifically to the case of the childhood educator's initial teaching. Certainly, in this field of application, the relationships found can contribute to the understanding of aspects, not sufficiently considered, that can influence the quality of teaching. Moreover, these results are found in an emerging country, in which this kind of study is rather scarce.
\end{abstract}

Keywords: Childhood educators, initial teaching, leadership styles, quality, multiple cases study.

\section{Introduction}

The aim of this introduction is to explore the concepts of leadership in the field of higher education and the relevance of this construct over the quality of early childhood teachers.

Nowadays leadership is considered one of the key factors for achieving quality in higher education institutions (Alzafari and Kratzer, 2019) since leaders have the ability to clarify roles and responsibilities, control the adequate allocation of resources, create partnerships and make improvements in persons and process management (Parvin, 2018). In this sense, Butler (2019) says that academic leaders must have technical, social, emotional and managerial skills since they are at the center of achieving the vision, mission and strategic objectives of these types of institutions (Adewale and Ghavifekr, 2019).

The practice of leadership has other effects to generate the more significant commitment of academics (Huang et al, 2020) and satisfaction and promotes academic results.

However, different levels of leadership coexist in higher education institutions, such as the senior leaders of these institutions, by one hand and the middle-range and the skills of Faculty leadership by the other hand.

In this area its proposed that these leaders must orchestrate the creation of strategic plans and allocate resources according to priorities (Sugrue et al., 2019), manage the demands and expectations of stakeholders such as the Faculty, the administration, the profession, students, international and government actors (Tellmann et al., 2020) and promoting an adaptive culture that embraces and balances the tension between innovation and operation (Tsai et al., 2019).

Huang et al. (2020) state that these increasingly play a more important role due to their proximity and daily contact with the members of their unit, which allows them to influence people and culture within the area for which they are responsible (Butler, 2019), thus helping to support a trustworthy relationship between the academy and human resources (Munir et al., 2019). Salmi and Pham (2019) 
argue that teaching leaders play an essential role in maintaining academic standards and in developing research and training programs as the core activity of this type of institution.

Transformational and transactional leadership theory has received widespread attention in the past three decades. Indeed, leadership style constitutes the leader's pattern of conduct that mobilizes followers to do what they have been required to do in pursuit of institutional goals (Anderson and Sun, 2017).

There are multiple ways to typify leadership styles, although a dominant perspective currently distinguishes between transactional leadership, transformational leadership, and passive-avoidance (Kahn et al., 2016). International evidence recognizes that transformational leadership can affect educational entities, mainly in: climate, culture, and academic performance, at the level of student achievement and student engagement, impactful in teaching processes and academic results (Ling and Ling, 2016).

Research indicates that leadership is considered a highly necessary skill to maintain the competitiveness of institutions, since the leader's role is not only limited to managing implementation processes, but is also in charge of supporting development and managing the change. Thus allowing new ideas to be generated and increasing the effort to achieve institutional effectiveness (Munir et al., 2019). In this sense, multiple authors recommend the incentive of this ability both in formal leaders especially in Faculty (see Butler, 2019; Cronje and Bitzer, 2019; Fam et al., 2019; Thornton, 2020 and Toni and Moodly, 2019).

On the other hand early childhood education is the foundation for the better life of the youngest children. (Gasper, 2020). Thus this area has a particular relevance to the study. Different researches show thar teacher training at university apparently fails in practice and in promoting skills, meanwhile society demands a new and competent form of education.

A considerable group of works focuses on learning and development programs implemented in educational institutions to encourage leadership in students, trough pedagogical projects as well as initiatives to encourage the development of this ability in academics. Here are studies carried out in countries such as the United States (Kearns, 2019), Canada (Corriveau, 2020), Australia (Butler, 2019), New Zealand (Thornton, 2020), Ukraine (Soroka et al., 2019), China ( Lin and Shek, 2019), South Africa (Cronje and Bitzer, 2019) and Spain (Pérez et al., 2019).

There are relevant evidence of the leadership styles and quality of university careers especially in developed countries. In contrast, there are no novel findings in the field of higher education in emerging countries like Chile.

The purpose of this research is to analyze whether the leadership style of academic department's directors is relevant or not to explain the quality of the childhood educator's initial teaching.

\section{Methods}

We made case studies by three programs of early childhood teaching from different university institutions from Chile. Quality of careers was related to the accreditations years from the National Commission of Accreditation CNA. We use Yin's recommendations (2014) in order to build the study and achieve internal validity, external validity and reliability. We conducted semi-structured interviews and a questionnaire: Besides we review the characteristics of careers and documentary background of the universities in the context of a grant Fondecyt 1180484 developed in Chile that support this research.

\section{Results and discussion}

In the higher education field there is a consensus about that leadership is considered a highly necessary skill to maintain the competitiveness of institutions, areas and departments, since the leader's role is not only limited to managing implementation processes, but is also in charge of supporting development, managing change and build a quality culture (Alzafari and Kratzer, 2019), thus allowing new ideas to be generated and increasing the effort to achieve effectiveness (Munir et al., 2019, Huang et al., 2020).

The research findings show that the transformational leadership style is associated with better quality of the formative processes. The relationships found reveal that the inspiring motivation, intellectual stimulation and individual consideration of the head of the department on which the teachers depend, influences in their degree of commitment, preparation and in the effort of the teachers in their classes and in their relationship with the students. These findings are consistent with the state of the art (see Cendra, 2020; Huang et al.)

Indeed, the analysis and findings show that the results are consistent with the state of the art, except for the fact that, in this research, the charisma of the director of the department does not seem to be a differentiating element that influences the quality of the formative processes. In turn, it should be noted 
that originality of this investigation lies in the fact that the impact of leadership styles is applied specifically to the case of the childhood educator's initial teaching. At the same time, schools need for social recognition, which is often denied, very few are able to carry out inclusive pedagogical project (Pedraja et al., 2012).

Chile is in debt with suitable human capital formation mainly due to the formation of the teachers, so the country should focus its efforts on pedagogical training and quality disciplinary in the careers of early childhood through from which the maximum potential of the students can be achieved so that they develop from a young age skills and competencies required in the knowledge society. (Rodriguez-Ponce et al.) As Gravett (2019) show the students want to be considering more than consumers in their careers.

However, the early childhood education field is still at an early stage of understanding in order to promote quality improvement inside the Faculty. As indicate Corriveau 2020, leaders must question their values, learn to take other people's views into account in their decisions, be transparent and develop a strong moral ethic. Certainly, in this field of application the relationships found, can to contribute to the understanding of aspects, not sufficiently considered, that can to influence the quality of teaching. Moreover, these results are found in an emerging country, in which this kind of studies is rather scarce.

\section{Conclusion}

The main conclusion is that the transformational leadership style is associated with better quality of the formative processes. Finally it can be argued that leadership styles are a key issue that through specific dimensions such as inspirational motivation, intellectual stimulation and individual consideration can influence the behavior of educators into the classroom.

Trough the literature review and the multiple case studies conducted we hope to contribute to the understanding of aspects, that can to influence the quality of teaching. Moreover, these results are found in Chile, in which this kind of studies is rather scarce.

In the future, research should be undertaken to determine another factors, like pedagogic isomorphism, that can influence to the quality of early childhood teachers.

\section{References}

Alzafari, K., \& Kratzer, J. (2019). Challenges of implementing quality in European higher education: an expert perspective. Quality in Higher Education, 25(3), 261-288.

Butler, J. (2019). Learning to lead: a discussion of development programs for academic leadership capability in Australian Universities. Journal of Higher Education Policy and Management.

Celdran, M. C. (2020). Leadership styles and job satisfaction in the colleges of nursing among the Universities In Zamboanga City. International Journal of Innovation, Creativity and Change, 11(7), 444-455.

Comisión Nacional de Acreditación-CNA. (2015). Criterios de evaluación para carreras y programas de pregrado. Retrieved May 30, 2020, from https://www.cnachile.cl/

Corriveau, A. M. (2020). Developing authentic leadership as a starting point to responsible management: A Canadian university case study. The International Journal of Management Education, 18(1). $1-10$.

Cronje, F., \& Bitzer, E. M. (2019). Continuous professional learning in private higher education: Making a case for distributed leadership. South African Journal of Higher Education, 33(2), 52-68.

Fam, D., Clarke, E., Freeth, R., Derwort, P., Klaniecki, K., Kater-Wettstädt, L.,... Horcea-Milcu A.I. (2019). Interdisciplinary and transdisciplinary research and practice: Balancing expectations of the 'old' academy with the future model of universities as 'problem solvers'. Higher Education Quarterly, 74(1), 19-34.

Gasper, M \& Walker, Rosie (2020). Mentoring and coaching in early childhood education. Bloomsbury Publishing Academic.

Gravett, K., Kinchin, I. M., \& Winstone, N. E. (2019). "More than customers": conceptions of students as partners held by students, staff, and institutional leaders. Studies in Higher Education.

Huang, Y.-T., Liu, H., \& Huang, L. (2020). How transformational and contingent reward leaderships influence university faculty's organizational commitment: the mediating effect of psychological empowerment. Studies in Higher Education.

Kearns, K. (2019). The leadership portfolio program at the university of Pittsburgh: teaching leadership to graduate students. Teaching Public Administration, 37(3), 255-273. 
Ling, S. \& Ling. M. (2016). The influence of transformational leadership on teacher commitment towards organization, teaching profession, and student learning in secondary schools in Miri, Sarawak, Malaysia, Educare, 4(2), 155-178.

Parvin, A. (2018). Leadership and management in quality assurance: insights from the context of Khulna University, Bangladesh. Higher Education, 77, 739-756.

Pedraja-Rejas, L.M, Araneda-Guirriman, C.A, Rodríguez-Ponce, Emilio R, \& Rodríguez-Ponce, J. (2012). Calidad en la formación inicial docente: evidencia empírica en las universidades chilenas. Formación universitaria, 5(4), 15-26.

Pérez-Ortega, G., \& Moreno-Freites, Z. (2019). Model of relationship of transformational leadership and university management. Dyna, 86(210), 9-16.

Rahnuma, N. (2020). Evolution of quality culture in an HEI: critical insights from university staff in Bangladesh. Educational Assessment, Evaluation and Accountability, 32, 53-81.

Ranjbar, M., Rafiei, S., Shafiei, M., \& Kargar, V. (2019). Transformational leadership style and employee creativity: a case study in yazd medical university. The health care manager, 38(3), 282-288.

Rodríguez-Ponce, E.R, Pedraja-Rejas, L.M., \& Ganga-Contreras, F.A. (2019). Determinantes, procesos y resultados de la formación inicial de profesores de enseñanza básica y educación parvularia en chile: una aproximación conceptual. Formación universitaria, 12(6), 127-140.

Salmi, J., \& Pham, L.T. (2019). Academic governance and leadership in Vietnam: Trends and challenges. Journal of International and Comparative Education (JICE), 8(2), 103-118.

Soroka, O., Kalaur, S., \& Balendr, A. (2019). Diagnostics of leadership qualities of specialists of" man-man" type of professions in military and civil higher education institutions: psychological and pedagogical approach. Romanian Journal for Multidimensional Education, 11, 264-277.

Sugrue, C., Solbrekke, T. D., Bergh, A., Sutphen, M., \& Fossland, T. (2019). University leaders' talk about institutional missions and academic developers' contributions. European Educational Research Journal, 18(6), 743-759.

Tellmann, S. M., Røsdal, T., \& Frølich, N. (2020). Professional educational programmes under pressure. Organizational challenges related to strengthening research. Studies in Higher Education, 1-11.

Thornton, K. (2020). Thank goodness it isn't just me - building a learning community for middle leaders. Journal of Higher Education Policy and Management, 42(3), 316-331.

Toni, N., \& Moodly, A. L. (2019). Do institutional cultures serve as impediments for women's advancement towards leadership in South African higher education?. South African Journal of Higher Education, 33(3), 176-191.

Tsai, Y., Poquet, O., Gašević, D., Dawson, S., \& Pardo, A. (2019). Complexity leadership in learning analytics: Drivers, challenges and opportunities. British Journal of Educational Technology, 50(6), 2839-2854.

Yin, R. (2014). Case Study Research: Design and Methods. California: Sage. 